\title{
Theorising Practice in Initial Teacher Education.
}

\author{
KIM SMITH \& ELAINE HODSON
}

Institute of Education, Manchester Metropolitan University, United Kingdom

k.e.smith@mmu.ac.uk

e.hodson@mmu.ac.uk

Resubmission to: Journal of Education for Teaching, December, 2009

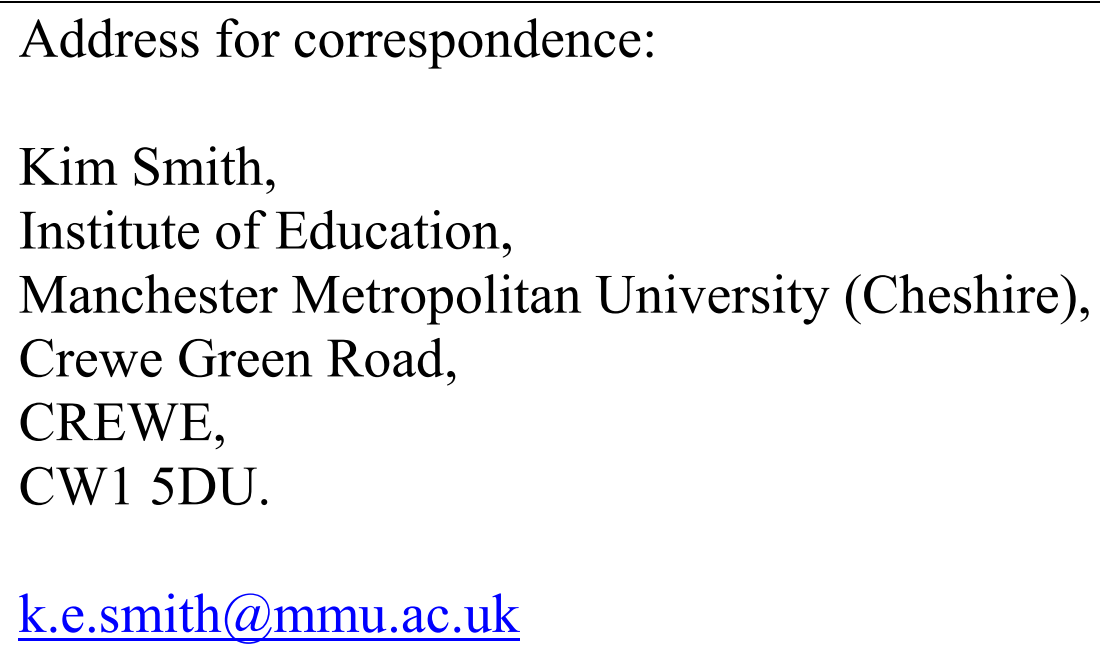

Address for correspondence:

Kim Smith, Institute of Education, Manchester Metropolitan University (Cheshire), Crewe Green Road, CREWE, CW1 5DU.

k.e.smith@mmu.ac.uk

Telephone 01612475187

8, 607 words excluding abstract $\&$ references

Not to be cited or quoted without the authors' permission. 


\begin{abstract}
Drawing on semi-structured interviews this small case study examines the perceptions of a group of trainees on the employment-based Graduate Teacher Programme (GTP) towards the close of their initial teacher education. Building on earlier work on the experience of secondary GTP trainees that had revealed trainees' ambivalence to 'theory', this paper examines what these trainees understood theory to be, and what they saw as the benefits from 'learning from experience', and more generally how they acquire professional knowledge. Findings suggest that GTP trainees were able to identify ways in which 'theory' had positively influenced their practice. Yet, we concur with Eraut's claim that most workplace learning occurs on the job and that this masks an uncertain interplay between formal and less formal elements of how trainee teachers learn on the employment-based GTP route studied here.
\end{abstract}

Keywords: Initial Teacher Education; Theory; Practice; Graduate Teacher Programme; Trainee Teachers 


\section{Introduction}

This paper is centred on considering an initial teacher education (ITE) programme that enables mature students to carry out their training primarily whilst employed in school contexts, towards examining how training parameters are redefined as a result of a university providing a supportive role. The Graduate Teacher Programme (GTP), an employment-based route for ITE, was introduced by the UK government in 1998 to offer an alternative for mature graduate entrants to university-based routes followed by the majority of students. The initiative came with a requirement for those registered on it to be employed in school, without an explicit partnership with a university, as is the norm on other routes. That is, the GTP is distinguished from other ITE routes in that trainees are truly employment-based as opposed to school-based: GTP trainees are employed, and most of their training happens, in school. With around 13\% (Training and Development Agency, 2009) of ITE provision now taking place within the GTP programme and its development likely to be continued into the foreseeable future (Freedman, Lipson and Hargreaves, 2008), serious consideration of what is possible regarding the GTP's contribution to the education of initial teachers is due.

Employment-based ITE routes have been criticised by some for replicating an apprenticeship model in ITE. The UK government's introduction of the articled and licensed teacher schemes, the forerunners of the employment-based GTP, in the late 1980s, prompted Furlong, Barton, Miles, Whiting and Whitty (2000) to suggest that their introduction 'had as much to do with challenging models of professional preparation as bringing in new populations' (p.46). For Furlong et al., the Licensed Teacher Scheme in particular posed a vision of professionalism 'that was highly pragmatic and rooted entirely in the experience of particular schools. As such it served ...to challenge traditional visions of professionalism sponsored by 
higher education' (p.65). The debate about the control of teacher education on a macro level, whilst drawing attention to important political and structural issues, is less helpful in generating understandings about learning how to teach in more school-based ITE. This is particularly so when one considers that since the 1990s, at least 2/3rds of each UK ITE programme has taken place in school.

We were drawn to this research by a desire to investigate a clear message which we heard being repeated by applicants to the Graduate Teacher Programme (GTP) within the provider in which we were working as university tutors: they were choosing an employment-based route into teaching in preference to a university led PGCE route of initial teacher education. When pressed on this at interview, they began to frame their responses in terms of being drawn to learning 'from experience' preferring to be 'hands on' and rejecting 'going back' to university, where they would be expected to learn from theory and at distance. This seemed to run counter to claims by some GTP trainees in an earlier study that more ‘theory' was needed (Smith and McLay, 2007). We therefore became interested in finding out, more precisely, why these trainees were attracted to 'hands on' training, and how exactly they might come to see any significance of theory in their development as teachers. The paper attempts to explore these concerns by first reviewing from the literature, trainee teachers' perceptions about the place of theory in their ITE. It then goes on to look at some theoretical models of learning to teach in ITE, before examining how these might be working in a case study of GTP provision, in context, and the implications of the case study findings.

Throughout the text the entrants will be referred to as trainees and their programme as training. This use of language is in no way intended to diminish entrants or the process in which they are involved, but rather reflects the preferred terminology of the UK's Training and Development Agency (TDA) in the Professional Standards for Qualified Teacher Status (QTS). It 
is perhaps worthy of note, that the particular GTP provider under study, as a matter of course, and subsequent to the time at which the data was gathered, now enrols all participants on the GTP for a university award at master's level: the Postgraduate Certificate in Teaching.

\section{Reviewing Trainee Teachers' Ideas about Theory}

Since our original attraction lay in the GTP trainees' rejection of spending yet more time in university, where they saw 'theory' as remote, we decided to examine earlier research which had investigated trainee teachers' ideas about theory. The growing movement in ITE in the UK in the 1970s towards a greater emphasis on practical experience in schools was fuelled, in part, by suggestions that trainee teachers valued school practice more highly than university-based aspects of their programme (Hobson, 2003). Not surprisingly, concerns about the UK government's intentions to move further towards school-based training in the late $1980 \mathrm{~s}$, led to research into the inherent value of the university contribution to the emerging professional competence of trainee teachers. Furlong's (1990) earlier study sought to identify the trainees' voice. He argued that the value placed on school-based experience by trainees did not lead to their rejection of 'theory' or discussion about the principles of practice; helping trainees to understand 'why things are as they are' was a role identified for the 'training institution', in this case, the university (p.92). However, the trainees wanted theory to be handled in a way which made more direct use of their own practical experience.

In some contrast, enthusiasm for the place of the university in ITE has been questioned. Again, in earlier work, McNally, Cope, Inglis and Stronach (1994) found little reference to higher education input or talk of 'critical reflection' in their conversations with secondary three or four year concurrent Diploma in Education trainee teachers on a final school placement in Scotland. 
They wondered whether the role of the university would have greater meaning, 'in-service', when confirmation of teacher status and managing basic practicalities for ITE trainees are in place.

From Scotland, but in common with Furlong's more positive conclusion, Holligan's (1997) study of primary undergraduate ITE trainees was designed to compare the trainees' understanding of theory with their overall competence as teachers. When questioned about the value of the university's educational studies provision, the students responded in terms of educational studies providing opportunities to think more deeply about issues as well as extending craft competencies such as classroom discipline. Holligan suggested that ideas are generated in university, whilst school discourses are based in practicalities; he further asserts that students tend to value practical experience above the study of educational theory since they struggle with practicalities in schools and not with ideas.

More positive still were the later findings of Furlong, Barton, Miles, Whiting and Whitty (2000) in which most of those students questioned regarded the place of university education, or 'theory' to be significant in their learning. Similarly, Williams and Soares (2000) study of secondary PGCE trainee, school-based mentor and university tutor views about the role of the university in school-based ITE makes another claim from all respondents for its positive role in trainees' learning about educational theory and their access to books and journals. Pitfield and Morrison (2009, p.31) additionally suggest from their research on more flexible ITE routes, that schools themselves subscribe to Furlong's notion that universities and schools offer 'different types of professional knowledge'. 
Returning to an earlier theme, Hobson's (2003) study based on questionnaires and interviews focusing on secondary history trainees from both school-centred ITE and university led partnership providers, concluded that trainees professed to value school-based experience most highly. These trainees identified reading theory as being of least value. In an attempt to illuminate the trainees' perceptions of the nature of theory itself, however, Hobson framed his study using a three-fold typology of interviewees 'in relation to their approaches to learning how to teach' (p.252). Whilst those trainees placed in the category of 'proceduralist apprentice' showed little interest in developing a broader understanding of education, and those in the category of 'understanding-oriented apprentice' conversely displayed an eagerness to engage with such issues, the majority of Hobson's trainees were placed in the category of 'education-oriented apprentice'. Trainees in this latter category believed that teachers need to acquire 'some 'background' or 'theoretical knowledge', in addition to the 'practice'” (p.254), but were not as effusive of theory as the understanding-orientated trainees. Consequently, the majority of trainees were prepared to acknowledge that understanding 'why' teachers might behave as they do may have at least some value. Hobson concludes, that since much research underlines the value of understanding theory for teachers, trainee teachers need to be challenged on their 'preconceptions about what learning and teaching ought to involve', before research can lay too much store by their judgements (Hobson, 2003, p.258).

In relation to trainee perceptions about the role of the university where it has been involved in the GTP, Smith and McLay's (2007) work points to most GTP secondary trainees studied valuing its contribution, particularly in presenting 'ideas for practice' and 'theoretical' input (p.49). The significance of the impact of the university on GTP trainees' teaching was explained by them in terms of the opportunity it provided for 'sharing ideas and discussion with colleagues and tutors' (p.51). However, unlike the PGCE trainees in the same study, four of the fifteen GTP trainees surveyed did not respond to questions about the university element of their 
training, suggesting that these GTP trainees may have had difficulty in separating 'training', at least in the university, from their view of 'practical experience'.

There is, for us, a clear message from the preceding discussion about how those trainee teachers, based mostly on traditional university led partnerships set up in the UK since the 1990s, view theory. Trainees do see a role for 'theory', in general, but the way in which they come to see its place may differ according to their individual dispositions about learning how to teach (Smith, 2001). Its role might also be different for particular individuals depending on the training setting they find themselves in at a given time. In this brief review, trainee teachers' ideas do not appear to attach intrinsic worth to theory per se; a much more utilitarian view of the term is applied.

\section{Learning to Teach in School-based ITE}

We turn now to what we have gleaned generally about some current thinking on learning how to teach and how this might be applied to more school-based ITE. One PGCE partnership in England which appears to have reformulated the notion of theory and how it ought to be played out in university and school is the Oxford Internship Scheme. Hagger and McIntyre's (2006) justification of this scheme follows the Furlong et al. (2000) study on Modes of Teacher Education conducted shortly after the introduction of more school-based teacher education in the UK during the 1990s.

Hagger and McIntyre claim that in the scheme, school is the setting where teacher education best takes place and that 'practical theorising' (p.58) by trainees to access their mentors' 'professional craft knowledge' (p.33) to develop personal thinking and practice is how it happens. What is most significant in trainee teachers' learning is that they work alongside experienced professionals in school to develop competence, ability to continue to improve 
practice and propensity to engage critically with proposed innovation. There is a belief that generalised theory can only partly inform the multifaceted approach used by teachers in a seemingly infinite variety of teaching situations. The scheme's view of 'theory' premised on 'professional craft knowledge' has been contested and countered (McIntyre, 1995) in a debate about what counts as teacher knowledge which goes beyond the scope of this paper. Here, like Hagger and McIntyre (2006), we adopt theory as 'professional craft knowledge', undoubtedly flawed, which due to its "personal particularity...can never adequately be coded... as a body of propositional knowledge. It is and must remain, knowledge-in -use' (p.35). Key to the development of 'professional craft knowledge' is that trainees engage in a process of searching, critical reflection or 'practical theorising' in order to frame questions, trial solutions and examine outcomes against more generalised criteria about practice, in practice itself. In this process of trainee teachers' learning, which we also support, the notion of school experience or school placement is abandoned.

Those elements which Hagger and McIntyre see as site independent might be covered at the university but, as well as acknowledging the university's role in providing access to published sources of propositional knowledge and teaching subject knowledge, they do cautiously suggest that 'university-based teacher educators have not shown themselves to be at all expert at ...thinking concerned with questioning the practicality of apparently good theoretical ideas' (2006, p.66). As university-based teacher educators, we would naturally wish to refute the generalisation about university-based teacher educators lacking expertise in questioning the practicalities of theoretical ideas. However, we would support their view that school-based teacher educators may be best placed to do this, and that university-based teacher educators have a key service role in supporting the school-based ITE curriculum. The latter do this by drawing 
on research -based knowledge, asking critical questions of practice and generating metacognitive understandings about the ITE enterprise as a whole.

Unsurprisingly, given their school-situated model of initial teacher education, Hagger and McIntyre's analysis gives weight to Lave and Wenger's (1991) formulation of 'legitimate peripheral participation' in 'communities of practice' (2006, p.46). The community of practice in ITE is where the school community, other teacher educators and trainee teachers co-exist to provide for their early professional learning. Once inside it, trainee teachers, in apprenticeship roles, come to engage socially with mentors and other experienced colleagues, to exchange their contribution to the work of the school and the wider endeavour of teacher education for personal professional expertise: a process of legitimate peripheral participation. Thus, trainee teachers are able to learn, incidentally, the skills, routines and cultures of teaching by being in school. But such incidental learning is fraught with difficulty due to what they see as the need for trainee teachers to subject 'craft knowledge... to sustained critical examination' (2006, p.48). Difficult questions asked of experienced colleagues by trainee teachers may be seen, they argue, to upset the balance of social relations in a community of practice. Eraut (2002, p.3) suggests, however, when writing about work-based learning more generally that the concept of 'community of practice' is flawed. In Lave and Wengers' conceptualisation, he argues, citing Engestrom (1999, p.12) 'the instability and inner contradictions of practice are all but missing'. He further feels that not all communities of practice will automatically lead to learning and that participation in them is not the only way to learn.

In order to provide space for trainee teachers to ask difficult questions, Hagger and McIntyre (2006, p.48) use Eraut's (2000) distinction between incidental learning and 'formal learning', where learning opportunities are planned, supported and executed, and where learning 
outcomes are specified and recognised through certification, to assert that all initial teachers' professional learning should be regarded formally. This runs counter perhaps to Eraut's later thesis that most work-based learning is 'on the job' and probably therefore less formal (Eraut, 2004, p.249). However, as Hagger and McIntyre (2006, p.50) acknowledge, there is room in Eraut's analysis for more 'deliberative learning' where time may to be set aside to engage in systematic reflection, planned learning activity, formal engagement with experience for learning and the formulation of learning goals. The discussion about how learning takes place across a range of settings has been usefully extended to question an assumed separation of formal and informal learning into discrete categories. Colley, Hodkinson and Malcolm (2003) argue that all learning episodes exhibit interplay between formal and informal attributes and that these are grouped in four aspects: location, purpose, content and process. This is a point to which we will return later.

In addition to questioning any singular view of formality in the process of trainee learning in school-based ITE, we are inclined to see Hagger and McIntyre's (2006) interpretation of the situated learning thesis as somewhat narrower than that offered by Putnam and Borko (2000):

"For some purposes, in fact, situating learning experiences for teachers outside of the classroom may be important, indeed essential, for powerful learning." (p.6)

Following Putnam and Borko's writing from North America, if what we think and do is linked to the situations we find ourselves in, there may be very good reason to challenge trainee teachers who are in schools less minded to work as a learning community, or less innovative school-based settings. Moving such trainees to a different school setting, or taking them out of school to view it from a distance with others within the initial teacher education community, would seem 
appropriate in such circumstances. This is particularly true, we feel, for initial trainee teachers. This is because their individual experience of teaching and learning how to teach may be limited and usefully supported with knowledge situated in different contexts, including that of the university. The proviso here would be that opportunities for forging understandings across contexts are amply provided.

To gain understanding and recognition of the learning undertaken through experience at work, we turn once again to Eraut's (2004) analysis of a range of learning projects in multiprofessional settings. This, we feel, although having much in common with Hagger and McIntyre's (2006) process of learning through 'practical theorising', may offer further insight about learning from the context of the school as work-place.

As what might be viewed as a subset of professional craft knowledge, Eraut draws attention to 'non-codified personal knowledge' as being significant in learning from experience. This concept includes: 'personalized versions of public codified knowledge...everyday knowledge of people and situations, know-how in the form of skills and practices, memories of episodes and events, self-knowledge, attitudes and emotions. [It also] focuses on the use value of knowledge rather than its exchange value in a world increasingly populated by qualifications.' (p.263). Here the role of the personal is arguably replacing the public as the value of exchange.

The analysis used by Eraut goes on to distinguish between experience or work activity and learning activity which tends to support professional learning and, by extension, the ability to theorise practically. Types of work activity identified which we feel are particularly beneficial to trainee teachers working in school are: contributing to group work and teams, working on specific goals and collaborative work in practice. Engaging in appropriately challenging and supported 
practice tasks, including formal study and working with clients as learners in classrooms, is also included. The types of successful work-based learning activity which were mostly embedded within the work activity noted above are: 'formal study, listening, observing, reflecting, practising and refining skills, trial and error, supervision or coaching, and mentoring. Problem solving...' (p.267). The distinctions are in ways overlapping and may sometimes be less than obvious. However, we feel that where learning activity denotes space for processing work activity, a distinction may be usefully made.

Research that has focused specifically on school-based training in schools frequently highlights the importance of skills employed by school-based mentors in moving learning forward in situated contexts. Mayotte's (2003) North American study of trainees coming to teaching as a second career highlights the mentor's role in steering trainees through the process of 'knowing why', 'knowing how' and 'knowing whom' by having an awareness of each career changers 'unique circumstances'. Similarly, Whitehead and Fitzgerald's (2006) study of TDA Training Schools (schools in England and Wales which acquire specialist status as a result of meeting particular criteria concerned with staff training and school student success), outlines the highly successful use of generative mentoring, where mentors provide not only models of effective teaching, but with the use of video, go on to model reflection on their practice. Within discussion on GTP training, Smith and McLay's study, 'getting the mentor right' appeared to be an essential part of how school-based training could be improved to meet trainees' training needs (2007, p.49); this was particularly true for the GTP trainees surveyed, although it is by no means clear whether the significance of the mentor for Mayotte's career changers could be applied to the GTP trainees who had 'changed' careers in the Smith and McLay study: many in the latter had previously occupied allied roles in school, were familiar with school culture and arguably less likely to need support in contextualising their experience. 
The process of identifying the GTP trainee's development needs in the context of their prior experience and then designing and executing an individual training plan is one which is recognised as being of value on the GTP in helping trainees learn how to teach (Mead, 2007; Ofsted, 2007). It is also a process which may be usefully linked to Mayotte's work on the importance of mentors mobilising the past experience of trainees to better understand their needs and the school-based training process. Indeed, Mead's study underlines the value placed by GTP primary trainees on discussions with mentors in developing their professional values and argues that this requires mentors to have reflective and dialogical skills. By extension, Mead implies that mentors also need to use their reflective skills to make links to central training through the mentoring process. We remember here, too, that Smith and McLay's GTP secondary trainees attached significant value to reflection and discussion provided within central university-based training.

What strikes us most significantly about the contribution of Eraut and others in its relevance for school-based ITE is the importance of individual agency and social exchange for trainee teachers and their teacher educators at school and at university. All partners would appear to need to be aware of the whole enterprise of learning in the work place, the culture at work and their place within it, as well as their own personal abilities, professional relationships and needs in accessing and transferring knowledge in and out of school, as a training setting.

We shall go on later to examine case study evidence in relation to the preceding discussion. However, before applying what we know about trainee teachers' perceptions about theory and learning to teach, it would seem sensible to visit the GTP case study in context. 


\section{The Case Study in Context}

We wanted to explore further whether those GTP trainees trained mostly in school and, in this case, working with a GTP provider linked to a university, would attach value to theory. For us, therefore, a key research question was how the GTP trainees would articulate theoretical and 'hands on' learning in learning how to teach. We were also concerned to shed light on what might be implied in relation to the role of school and university in bringing about the learning of GTP trainees and initial teacher education trainees generally.

Most GTP trainees engaged with the local authority, school and university led employment-based provider involved in the study reported here, were registered on a three term (one year) programme in the north-west of England in the academic year 2006-7. The ITE training programme for this provider was largely undertaken in a lead school and there was a second school teaching experience, a block of 6 weeks taken in the first part of term two. Central training (about $15 \%$ of all training time) happened within the partnered university and consisted of 24 hours ( $12 \mathrm{x}$ two hr slots) of general professional studies training for primary GTP trainees. Secondary trainees, received 24 hours of central training divided into 12 hours of subject training and 12 hours of general professional studies training

Central training was designed to complement in-school training in content and form; it was framed using the TDA's Professional Standards for initial teachers, plus wider theoretical considerations, and provided a vehicle through which the practice in single schools and departments might be shared, reflected upon and discussed. In-school training time was highly individualised, involving a range of structured (for example: mentor sessions, pupil tracking, observations of experienced colleagues and formal observation of trainees' teaching) and less formal activity (e.g. self-study tasks, informal conversations with key teacher co-ordinators and 
experienced classteachers). Training time in school (about $85 \%$ of all training time) was provided as a percentage of the trainee's whole timetable in school, typically moving from $70 \%$ in term one to $30 \%$ in term three. Central training was linked to in-school training through a series of study tasks. The GTP trainee's training was encompassed within an individualised training plan.

A Professional Mentor, a senior experienced school colleague, was responsible for the GTP trainee's individual in-school training and assessment programme. Secondary trainees were also allocated a school Subject Mentor, someone with expertise as a teacher and school-based trainer in the subject of training and responsible for the day to day subject support and assessment of the trainee. University Professional Tutors visited trainees and their mentors once each half term to moderate trainee progress and to monitor the implementation of in-school training. Secondary trainees received one of the two visits each term from a Subject Tutor, who would moderate and monitor subject specific aspects of the trainee's teaching progress and training.

Seven trainees were selected (four primary and three secondary) according to their Professional Tutor's perception of their commitment to participate in the study. By definition, all the GTP trainees were graduates, mainly of UK universities, and had therefore had experience of academic study. It is important to be aware, however, that this experience of study was far from homogenous ranging from part-time to full time and encompassing different institutions and subject areas. Nevertheless, all had existing experience of being university students in one guise or other. The majority of the GTP trainees had also experienced life as employees. Many of them had already worked in schools in allied professional roles, as teaching assistants (TAs) or learning mentors; others had been employed in industry or commerce and had gained the required school experience as parents or volunteers. It seemed therefore that the choice of an employmentbased initial teacher training route had been well informed and worthy of investigation. 
Our belief was that the best way to examine the views of the GTP trainee was through discussion in a fairly informal environment. We chose to conduct a series of semi-structured interviews, thereby conducting our research by drawing on the relationships already in existence on the programme between tutors and trainees. A time and venue for the interview was negotiated but, in all cases, trainees were happy to be interviewed in the schools in which they were training. The trainees, at this stage at the end of their one year programme, had become used to visits from tutors as part of their progress reviews and were very familiar with the process of entering into professional dialogue relating to their programme. The interviews were conducted following final assessment (for these particular trainees all successful), in order to ensure that the trainees were not inhibited in their responses by fear of ensuing judgements. The semi-structured nature of the interview ensured that we were able to probe responses as we felt appropriate.

As university tutors associated with the GTP provider concerned, we undoubtedly must declare an interest in its operation, although we have attempted to view the work critically, throughout. Our aim was, and is, to make the training experience of the GTP trainees involved more explicit. Interview questions were focused around the following: what motivated them to select an employment-based route, how GTP trainees conceived of and valued learning from theory and learning from practice, what had helped them develop as teachers on an employmentbased programme and in which ways. Trainees were also asked about the value of their second school experience since this had previously proved significant for a number previously registered on the GTP under study. The research findings are based on data collected. Each interview was analysed independently, and then jointly, to identify emerging common themes. These themes are discussed in turn below.

\section{Discussion}

Theme 1: the role of 'theory' per se 
When invited to comment on what 'theory' meant to them, all interviewees were able to refer to theory acquired during the programme. They offered a variety of definitions of theory, including, for example: 'published work', 'carefully collected and valued evidence' and 'reasons we do things'. One physical education trainee seemed most concerned with subject knowledge content as theory; for him, theory defined what should be taught. This is probably because teaching 'theory' has a particular meaning in PE, one which is separated from the 'practical':

"Theory is the [exam] specification - what they need to know. I would want more subject knowledge on Dance. This is something I've worked on with the subject teacher."

Trainees did not make any explicit reference to 'practical theorising' as articulated by Hagger and McIntyre (2006) or the relationship between this and 'hands on' learning, but this may be concerned with a theory-practice dichotomy presented or interpreted through the interview questions. It might also point to a need to make the process of 'practical theorising' more explicit within the GTP under study. It did not mean that the trainees questioned were not able to engage in this process. Indeed, the last paragraph in the discussion of the next theme would suggest that trainees questioned would welcome more of such development.

All trainees referred to the theory they had been introduced to at university central training sessions as useful. In terms of access to theory as published sources, more reference was made to material accessed electronically through the university as being accessible than books borrowed from any of the university's library sites. As trainees were distant from the university and training 'on the job', this is to be expected and conveys an important message about the accessibility of published sources for GTP trainees and their schools. It also points to the need to further develop the use of such sources.

There was no suggestion that theory was unhelpful, or to be avoided. We became aware during the course of our discussions that we ourselves, as university tutors responsible for central 
training, might well be regarded by the trainees as guardians of the very theory that we were suggesting they may be rejecting. This might make any criticism from trainees of the relevance of theory seem like an indirect and 'to be avoided' criticism of us. The emphasis on process in the central training is on reflection and analysis, where we, as 'teachers' on that part of the programme delivered at the university, might also be seen by the trainees as practitioners sharing their, and our, own concerns about teaching. Also, as part of this process, we introduced alternative theoretical perspectives to those derived from individual training contexts. Through the discussion so generated, we hoped to pose a challenge between 'theories of action' (what is believed to work) and 'espoused theories' (those aligned with perceived, more general, ideals) (Eraut, 2008). We hoped therefore that trainees would feel sufficiently immersed in our interpretation of 'practical theorising' to engage in a reasoned critique of theory, wherever originated.

This culture of reflection appeared to the extent that each GTP trainee was able to give examples of the way they thought theory had positively influenced their practice. Areas cited were often focused on pragmatic concerns, for example: 'assessment for learning', 'learning styles', and 'brain-based learning'. Such areas may have been generated by topical concerns in individual schools. On more than one occasion, trainees spoke of their own theoretical research being shared with colleagues in both formal and informal ways, although it is not clear which, if any of these ways of sharing had a further impact on trainees' learning.

The ways in which theory had influenced their practice tended to be expressed in terms of being presented with, or researching, ideas which were then matched to previous practice experience to provide a framework of support for their teaching. Ideas so generated could also be trialled with confidence in the classroom: 
"Its valuable to be as well read as possible - part of the teacher's role. There's an element of the 'natural', but a lot needs to be learned. I prefer the back up and reassurance...to keep you on the right track."

One trainee suggested that more provision of theory was needed, but went on to say perhaps more expertise might be shared within the school. We have taken from this that although the trainee concerned recognised and valued the work of experienced professionals within the school, she felt that opportunity to share ideas about this in school were fewer than desired. This is very interesting when set alongside the finding that what appeared to be most significant to trainees' learning seemed to be opportunities when they were able to discuss theory as it applied to their own context, in school, perhaps irrespective of its source. Instances of this cited were group or individual discussions with mentors, discussion during tutor visits, discussion with peers (when more than one trainee was in a school), and discussion with school- based colleagues following central university sessions. This finding is supported by Smith and McLay (2007) and Mead's (2007) work, in which GTP trainees were found to attribute value to reflective discussion of practice, although it is less clear in making a connection to these earlier findings how or whether GTP trainees may attach relative value to the context, (in or out of school) in which the discussion occurs. What seems likely, in common with the theme discussion on 'learning from experience' which follows, is that the place of theory in the GTP provision under study at least, is best valued by trainees when it may be interpreted and reworked in situ. The Hobson et al. (2008) finding that school-centred initial teacher training programme trainees were significantly more likely than those trainees on other more traditional ITE routes to see the relevance of theoretical elements to their practice tends to support this view. University and school would certainly assist trainees further if they were to recognise and work within a framework of trainee learning which builds on such findings.

\section{Theme 2: learning from experience}


Responses from GTP trainees to the question about how learning from experience 'hands on' actually worked for them were typically concerned with the intensity and continuity of training which is employment-based. The intensity appeared to arise from the immediacy of working in classrooms with mentors, other experienced colleagues and young people. It also came from a sense of belonging to the whole school. The GTP trainees spoke of the value in observing colleagues' teaching, of being able to ask questions of others' practice, in working collaboratively with colleagues in classrooms and in being introduced gradually to teaching independently. Although much of this 'hands on' training concurs within the working activity identified by Eraut (2004), there is a need, highlighted by Eraut (2008), to encourage awareness of what is being learnt through engaging in 'learning actions', for example through questioning or justifying observations, rather than simply observing practice. This enhancement of work-based learning is to some extent dependent on the co-investment of trainee and mentor, or experienced colleague. Getting to know the class and the reactions of young people to the GTP trainees' teaching were also mentioned as significant. This was particularly so for some GTP trainees at the point at which they began to see their teaching as their own: 'when you know what you want to do and what kind of outcomes you want to get', once again registering the importance of individual agency in learning how to teach. For others, training was not just about visiting the school to practise teaching for a little while and then moving out, as was perceived by GTP trainees to be the case by on a traditional ITE route; there were policies and systems to be picked up and adhered to, thus underlining the significance of playing a full professional role in school. Indeed, both Ofsted (2007) and Mead (2007) draw attention to the strong commitment shown by GTP trainees to their training and their schools. Continuity was typically expressed by trainees in terms of the nature of the training time which the GTP provided. In simple terms, there was more opportunity in the lead school for those learning to teach to try things out and this served to encourage further trials; the GTP was therefore observed to make for, in the words of one trainee, 'braver practitioners': 
"The Professional Mentor was really supportive - knowledgeable and set tasks followed by observation and feedback. [She'd say] find out as much as you can about each student, not just their behaviour. Now do it. She'd observe me and boost my confidence."

GTP trainees did acknowledge in various ways that trying things out was, on its own, an insufficient prerequisite for transforming their practice. Some spoke explicitly about the value of having or making time to reflect on practice. Most others, whilst not mentioning reflection as such, did talk positively about evaluating their own lessons and, or, the significance of feedback and challenge provided by mentors. The sense of 'getting the mentor right' on the GTP, highlighted by Smith and McLay (2007), is echoed here. Indirectly, their responses during interview questions, particularly concerning the question about the value of the second school for their learning, demonstrated a key place for self-reflection in their own development. Specifically, thinking about practical strategies that they derived from mentors and experienced colleagues at school, from university sessions, and, in some cases, published material, were viewed as being important to GTP trainees' learning from experience.

\section{Theme 3: impact of second school}

Although the trainees interviewed reported surprisingly high feelings of trepidation about moving to a second school, with hindsight it was generally viewed as a very positive experience:

"I enjoyed my second placement - felt like I'd come on in leaps and bounds as a result of that. I had loads of encouragement and praise. It added a sense of confidence coming back here, having realised I could do it elsewhere."

A significant reported reason for this was that being treated differently by colleagues at the second school, often with higher expectations of their teaching ability, raised their self-esteem. This would appear to indicate that the balance between the triangle of support, confidence and challenge, referred to by Eraut (2004) as being significant for professional learning in the workplace, is perhaps unsurprisingly complex where two schools are involved in training. It suggests that the challenge presented by a partial break in social relations with the lead school, at an 
appropriate stage of trainee competence, allows trainees to apply their skills independently in a new setting. Also, it suggests that theory developed in the lead school setting might be used and further developed when it is possible for trainees to apply this in a second school. Evidence in favour of such challenge is further supported by the fact that trainees also reported being able to experiment with the skills they were beginning to acquire in their lead schools at the second school, without feeling self-conscious; there was perhaps less risk involved if relationships were less well formed there. Indeed, one GTP trainee reported feeling like a 'visitor' in the second school, compared with feeling like a 'teacher' in the lead school. The notion of 'visitor' could of course be interpreted negatively for the trainee concerned.

In terms of learning activity across schools, if a GTP trainee at a second school had overlapped with another GTP trainee at the same school, this was seen to be a positive opportunity for professional dialogue. Where mentoring time was made available in the second school, this proved highly invaluable, offering as it did a contrasting professional view. Whilst some trainees noticed a difference in the mentoring strategies applied in each of the lead and second school, mentoring strategies in the second school were generally not reported and perhaps, therefore, less significant. Assuming mentoring was available in the second school, the finding is interesting because it suggests that individual dispositions to learn and the 'informal' connections with colleagues other than mentors may be more, or as, significant to trainee learning than formal interaction with mentors, at least at the second school. It may also indicate that when more formal mentoring structures are not in place, or less evident, some trainees will inevitably use wider networks of support from experienced colleagues. This resonates with our interpretation of the significance, but not exclusivity, of the less formal in Eraut's position. It also suggests that recent attempts by the TDA to define 'training' on employment-based ITE as something with a planned, formal outcome may result in only partial capture of what is actually learned by trainees in school. 
Other outcomes of professional learning at the second school included gains from experiencing a contrasting school context, a requirement of the training programme. Eraut (2008) refers to this as 'divergence of experience and of meaning' by which an original community of practice, such as that found in the lead school, may be challenged or enriched. Experience gained in lead schools may result, if left unchallenged, in a 'deceptive discourse' which prevents further reflection. Reflection helped the trainees to see differences in school thinking and practice, and also to identify theories which spanned their own practice across schools. On return to the lead school, some individual trainees mentioned being able to contribute new knowledge and skills there as a direct result of the second school experience:

"Here [lead school], 'assessment for learning' is just another acronym. I've since come back and done tutorials for the department on that strategy, and others have put it into effect."

Another reported, on his return to the lead school, 'knowing who he was as a teacher'. Some trainees were therefore clearly able to apply skills gained at the second school and to articulate this as new professional learning and an enhanced professional identity. Given the significance of the second school for trainees' professional learning reported here, we feel there is a strong argument for ensuring that GTP trainees' second school experience and training, and its relationship to that in the lead school, enjoys close attention.

\section{Theme 4: choice of route}

All but one of the seven GTP trainee teachers interviewed had had substantial prior experience in school, most for one year (range four weeks part-time to four years full-time). They had worked as unqualified teachers, teaching assistants, learning mentors, or in technical roles. With one exception, each was training in the school in which they had previously been employed in an allied role. 
Surprisingly, three of the trainees interviewed had not been aware of the GTP prior to selecting the route and had been introduced to it through colleagues in school. This finding prompts a further question about whether the trainees would have been at all motivated or able to train to teach had they not been 'sponsored' by their schools; it also provides some justification for the GTP meeting a particular need for some as an alternative route into teaching (Smith and McLay, 2007). Significantly, it raises an issue about the accessibility of the route in general. All trainees had prior connections to the school in which they eventually trained on the GTP and spoke of the significance of good relations built with teaching staff and young people as being significant in their choice of route. Indeed, one spoke of the GTP as a privileged opportunity, perhaps reinforcing the strength of connection with the school. It may therefore be argued that the schools were highly influential as a source of information for, and in guiding the selection of, the ITE training route for these GTP trainees. As a consequence, a positive sense of obligation to train in the schools was generated within the trainees concerned. One aspect of Eraut's 'noncodified personal knowledge', that relating to the everyday knowledge of people and situations, can be readily applied to the GTP trainees in this study, as can his reference to the significance of the schools' commitment to trainees in raising their confidence (2004). These features were undoubtedly significant in helping them to make an application to train on the GTP. When combined with the economic imperative of a regular unqualified teacher's salary which training on the GTP provides, the seduction of the GTP is a very real one for certain ITE trainees. Without exception, the GTP trainees spoke of the perceived 'hands on' way of learning afforded by the programme as being a prime consideration in their choice of route.

Of the group, four of the trainees indicated that they felt they had already begun the process of learning to teach and that training in what for almost all was their existing workplace would provide the continuity which would allow them to make faster progress. One felt that the 
individualised nature of training on the GTP was an asset in furthering learning, as opposed to the 'one size fits all' perception of training on a traditional PGCE route. There was however, unlike our initial assumptions in preparing for this paper, no emphatic or widespread rejection by GTP trainees of traditional, 'theory-based' teacher training routes. Interestingly, one primary trainee with four year's experience as a teaching assistant would have preferred no training, on any route, at all. What seemed most important to trainees in choosing a training route was the relationship already built with the teachers and young people at the lead school; in effect, the school, and, by extension, the GTP route, appeared to have chosen them.

The finding about trainees' choice of route clearly signifies for us that there are different understandings about the relationship between training and experience, as indicated earlier by Smith and McLay (2007), amongst those registered with the GTP provider under study and that there is a need to make the nature and value of professional learning in the workplace explicit. This is particularly true in schools where time and space for reflection are not made available and may be further complicated through the application of workplace cultures (Eraut, 2004).

\section{Conclusion}

Extrapolating from our reading of Eraut (2004) and following Colley et al. (2003), it seems that Eraut's claim that 'most workplace learning occurs on the job' (p.249) masks an uncertain interplay between formal and less formal elements of how trainee teachers learn on the employment-based GTP route studied here. For us, and unlike our understanding of Hagger and McIntyre's thesis, formality is probably necessary, but not an exclusive part of 'on the job', or more school-based, teacher training. Formality in learning is necessary, partly because of the national regulation of all initial teacher education in the UK and the requirements of individual training providers. It resides in the model of learning espoused by the provider. It is also necessary due to the positioning of the trainee teacher as 'learner' in school-based settings where, 
typically, only school students are permitted to be learners in classrooms. Trainee teachers learning in school-based settings, particularly those on employment-based routes assigned to full professional roles as 'colleagues', are therefore reliant on the provision of formal spaces, such as scheduled 'off the job' discussion with mentors, in which their needs as learners may be recognised. For this reason, the mentor's role in employment-based training as underlined by Smith and McLay (2007) and Mead (2007) must be recognised and developed. Such formal spaces must definitely be provided in school, but they must also be provided to allow distanced and cross-school discussion in ways which challenge and extend the specific in school-based and employment-based training settings.

Informality in learning resides, for us, in individual agency and dispositions which trainee teachers bring to their experience in and out of classrooms and schools. It is through these that they interact with peers, mentors, other teacher educators and other experienced colleagues engaging in, for example, self-study, discussion, observation, review and more formal training, to learn how to teach. Key to the existence of a process of practical theorising and hence individual learning on the GTP in this study was the extent to which trainees were able to recognise their own development as shifting in relation to the impact their teaching was having on young people. Evidence for this ability was varied and partly reflected the highly individualised nature of each trainee's training programme and their response to it. That most trainees were able to value a process of reflection on practice beyond direct experience which included reference to sources outside their lead school, is a sign that the formal model proposed by the GTP provider here is enjoying some success. However, there are indications that trainees would be better able to articulate the meaning and impact of theory on practice if more opportunity for discussion about the relevance of theory for their schools and classes in school was provided.

\section{Implications for the GTP Provision}


Some implications emerge from the small case study and discussion above which may not be readily applied to all GTP provision, or to ITE generally. However, we are confident of the following indications for those GTP trainees interviewed in the local authority, school and university led GTP provider concerned:

A key strength of learning to teach on the GTP is that trainees are literally immersed in a range of work and learning activity at school and, through the provider's central training under study here, across schools. This immersion provides trainees with exceptional access to valued information from professional sources such as members of the school and university teaching staff; they also enjoy opportunity to trial teaching and learning with many of the same young people continuously for the duration of their training programme. The issue indicated here, through the significance of the second school experience, however, is the extent to which immersion allows for challenge in trainee development such that alternatives to practice might at least be considered. Those lead and second schools offering similar GTP provision might wish to further consider the range of alternative practice they can offer and make accessible to trainees within their schools. Lead schools might also wish to review their choice, training activity and working relationship with a second school to maximise trainee development opportunity provided there. Where GTP providers are linked to universities, as in this study, or where the provider offers provision equivalent to that typically expected from a university setting, providers may benefit from reviewing the nature and frequency of central training, as Mead (2007) also suggests. Such central training would appear to need to support a view of alternative practice through discussion linked to a range of theoretical sources, including published source material. Providers might also consider how a model of practical theorising is made explicit and used across the provision by all partners, particularly school-based mentors. 
The notion of choice in relation to choosing the GTP ITE route is somewhat misleading. Schools tend to select their GTP candidates who are, more often than not, willingly obliged to enter ITE through the GTP route. As GTP trainees tend to be drawn from the schools in which they have previously worked in allied roles, this provides both strength and strife for professional learning on the GTP. Strength in relation to candidate selection derives from the close professional and personal relationships between colleagues and young people in the schools. Strife may also come from such relationships, as evidenced through an emotional barrier to risk taking in professional learning by some trainees. Strife is similarly evidenced in confused assumptions about school experience and professional learning in school. Careful counselling concerning the relative contributions of all ITE routes for candidates and schools and more explicit reference to what professional learning from school experience might involve prior to application to the GTP is suggested.

\section{Acknowedgement}

We would like to thank Professor Tony Brown, Institute of Education, MMU for his valued comments on earlier drafts of this paper.

\section{References}

Colley, H., Hodkinson, P.\& Malcom, J. 2003. Informality and formality in learning: a report for the Learning and Skills Research Centre. The Learning and Skills Research Centre. http://www.LSRC.uk Accessed $20^{\text {th }}$ October, 2008.

Engestrom, Y. 1999. Perspectives on activity theory, cited in Eraut, M. 2002. Conceptual analysis and research questions: do the concepts of "learning community" and "community of practice" provide added value? University of Sussex: Educational Resources Information Center, EA 031 732, p.5.

Eraut, M. 2000. Non-formal learning and tacit knowledge in professional work, British Journal of Educational Psychology, 70: 113-36, cited in Hagger, Hazel \& Donald McIntyre. 2006 Learning teaching from teachers: realising the potential of school-based teacher education. Maidenhead: OUP, p.50. 
Eraut, M. 2002. Conceptual analysis and research questions: do the concepts of "learning community" and "community of practice" provide added value? University of Sussex: Educational Resources Information Center, EA 031 732, p.5.

Eraut, M. 2004. Informal learning in the workplace. Studies in Continuing Education 26, no.2: 247-273.

Eraut, M. 2008. An epistomology of practice, paper presented at Manchester Metropolitan University, $17^{\text {th }}$ May in Manchester, England.

Furlong, J. 1990. School-based training: the students' views. In Partnership in initial teacher training, eds M. Booth, J. Furlong \& M. Wilkin, 87-98. London: Cassell.

Furlong, J., L. Barton, S, Miles, C. Whiting \& G. Whitty 2000.

Teacher education in transition: reforming professionalism? Buckingham: Open University Press.

Hagger, H. \& McIntyre, D. 2006. Learning teaching from teachers: realising the potential of school-based teacher education. Maidenhead: OUP.

Freedman, S., Lipson, B. \& Hargreaves, D. 2008. More good teachers. Policy Exchange. http://www.policyexchange.org.uk. Accessed 20 $0^{\text {th }}$ October, 2008.

Hobson, A. J. 2003. Student teachers' conceptions and evaluations of "theory" in initial teacher training (ITT). Mentoring and Tutoring 11, no.30: 245-261.

Hobson, A. J., Malderez, A., Tracey, L., Giannakaki, M., Pell, G. \& Tomlinson, P. D. 2008. Student teachers' experiences of initial teacher preparation in England: core themes and variation. Research Papers in Education 23, no.4: 407-433.

Holligan, C.1997. Theory in initial teacher education: students' perceptions on its utility - a case study. British Educational Research Journal 23, no.4: 533-551.

Lave, J. \& E. Wenger 1991. Situated learning: legitimate peripheral participation. Cambridge: Cambridge University Press.

Mayotte, G.A. 2000. Stepping stones to success: previously developed career competencies and their benefits to career switchers transitioning to teaching. Teaching and Teacher Education, no.19: 681-695

McIntyre, D. 1995. Initial teacher education as practical theorising: a response to Paul Hirst. British Journal of Educational Studies 43, no.4: 365-383.

McNally, J., Cope, B., Inglis, W. \& Stronach, I. 1994. Current realities in the school teaching experience. Teaching and Teacher Education 10, no.2: 219-230.

Mead, N. 2007. How effectively does the Graduate Teacher Programme contribute to the development of trainees' professional values? Journal of Education for Teaching: international research and pedagogy, 33, no.3:309-321. 
Ofsted 2007. An employment-based route into teaching, 2003-6.Ofsted. http://www.ofsted.gov.uk. Accessed $27^{\text {th }}$ April, 2008.

Pitfield, M. \& Morrison, L. 2008. Teachers' experiences of mentoring on a flexible initial teacher education programme: implications for partnership development. Journal of Education for Teaching: international research and pedagogy 35, no.1, 19-32

Putnam, R.T. \& Borko, H. 2000. What do new views of knowledge and thinking have to say about research on teacher learning? Educational Researcher 29, no.1: 4-15.

Smith, K. 2001. The development of subject knowledge in secondary initial teacher education: a case study of physical education student teachers and their subject mentors. Mentoring \& Tutoring 9, no.1: 63-76.

Smith, K. \& McLay, M. 2007. Curates' eggs? Secondary trainee teachers' experience of the Graduate Teacher Programme and the Postgraduate Certificate in Education. Journal of Education for Teaching: international research and pedagogy 33, no.1: 35-54.

Training \& Development Agency. 2009. Personal electronic correspondence: TDA Census Team.

Whitehead, J. \& Fitzgerald, B. 2006. Professional learning through a generative approach to mentoring: lessons from a Training School partnership and their wider implications. Journal of Education for Teaching: international research and pedagogy 32, no.1: 37-52

Williams, A. \& Soares, A. 2002. Sharing roles and responsibilities in initial teacher training: perceptions of some key players. Cambridge Journal of Education 32, no.1: 91-107. 
